\title{
Analytical Study on Electro Discharge Dressing (EDD) of large-grit size CBN wheels
}

\author{
N. Ortega", J.A. Sánchez", L.N. López de Lacalle*, J.A. Marañón"*, X. de Maidagan ***
}

(Received on June 2, 2004)

"Department of Mechanical Engineering, Faculty of Engineering of Bilbao, University of the Basque Country,
48013 Bilbao, Spain.
*"Research Director of IDEKO, Elgoibar, Spain.
** ONA ELECTROEROSION S.A., Eguzkitza s/n, 48200 Durango, Spain.

\begin{abstract}
Electro Discharge Dressing (EDD) and other electrical methods (ECDD, ELID) are commonly applied to the trueing/dressing of superabrasive grinding wheels. Although the feasibility of EDD in the dressing of large-grit size wheels has been suggested, little valuable information can be found. In this work, the application of EDD to large-grit size $\mathrm{cBN}$ wheels using different dielectric fluids (deionised water and minimal quantity of grinding emulsion) is analysed. The different types of discharges that appear are identified and classified. The stability of the process is assessed in terms of the percentage of discharges of each type, and the statistical distributions of ionisation time and discharge current. The influence of electrode size, wheel speed, on-time and discharge current is studied for each dielectric fluid. The grinding performance of the EDD'ed wheel (deionised water) is largely improved with respect to that of conventionally dressed wheels, the results showing a reduction as high as $42 \%$ in the forces, which is related to the high grit protrusion obtained.
\end{abstract}

Keywords: Electro Discharge Dressing, cBN wheels, grinding forces, Large-grit size

\section{INTRODUCTION}

In the last decades, the development of superabrasive grinding has opened the door to new applications in the grinding of extremely hard and difficult-to-grind materials with very tight tolerances and surface finish. Processes such as HEDG (High Efficiency Deep Grinding) or the so-called QuickPoint have only been possible after the technology of superabrasives (diamond and cubic Boron Nitride, $\mathrm{cBN}$ ) has been available.

The market for superabrasive wheels is growing day after day. Conventional grinding is a good choice when it comes to the grinding of hard materials, up to $50 \mathrm{HRc}$. However, the results obtained when using $\mathrm{Al}_{2} \mathrm{O}_{3}$ or $\mathrm{SiC}$ wheels for the finishing of ceramics and aerospace materials (such as Ni-based alloys, Co-based alloys, etc.) can be clearly improved by using superabrasive wheels.

The hardness of cBN (4700 HK) is only below that of diamond. The most remarkable properties of cBN as abrasive material are high wear resistance, very high thermal conductivity and good thermal stability even at very high temperatures. As a consequence, $\mathrm{cBN}$ wheels exhibit very low wear if compared with $\mathrm{Al}_{2} \mathrm{O}_{3}$ wheels. Moreover, thermal damage of the workpiece is minimized, and the surface integrity of the ground component, improved ${ }^{1)}$. Finally, if compared with diamond, $\mathrm{cBN}$ shows no chemical affinity with ferrous materials.

No doubt, the use of diamond and $\mathrm{cBN}$ wheels can improve greatly the performance of the grinding process, but at the same time, new problems must also be faced. Together with the need for new machine concepts, including stiffer structures, higher spindle speeds, ultra-high precision advanced higher pressures and flow rates, the trueing/dressing of these expensive wheels must also be addressed.

Mechanical dressing using diamond, $\mathrm{SiC}$ sticks or even steel casting blocks, is commonly carried out. However, this method shows important limitations in the case of superabrasive wheels, amongst which the following can be mentioned:

- High wear of the dressing tool, increasing the cost of the operation, the non-productive times and introducing uncertainty in the accuracy of the final part.

- High dressing forces, that affect the precision of the operation.

- Limited protrusion of the grits (around 20$30 \%$ of the size of the grit $\left.^{2}\right)$, which results directly in lower material removal rate, higher grinding forces and surface damages on the work part ${ }^{1)}$.

In order to overcome the above-mentioned limitations, a number of non-conventional dressing techniques have been developed in the last two decades. Some of those techniques are commented on in the following paragraphs.

Murata et $a l^{3}$ presented a paper on electrochemical effect for removal of bonding material, among the early studies on the electro-chemical dressing process. The electro-chemical dressing is characterized by its high dressing rate. Since then, the ELID (electrolytic in-process dressing) method was invented by Ohmori ${ }^{4)}$. The ELID was presented as an electrolytic dressing for mirror surface grinding in its early stages ${ }^{4,5)}$. For this purpose, its electrolytic effect works as moderate dressing for small-grit size wheels under specific conditions. 
Through the selection of the electrolytic nonlinearity, the ELID also successfully enabled coarse and efficient grinding ${ }^{6), 7}$.

ECDD (Electro Contact Discharge Dressing) was introduced by Pachalin $^{8)}$ in 1987. In this case, a DC is applied between the wheel and a conductive electrode. There is mechanical contact between the wheel and the electrode, in such a way that the electrode is ground by the wheel. Sparks appear between the material removed from the electrode and the wheel, thus removing bonding material from the latter ${ }^{9}$. The efficiency of ECDD has been proved for grit size below $50 \mu \mathrm{m}$, resulting in a clear reduction of grinding forces and minimising the damage induced on the ground surface ${ }^{10), 11}$. Some studies $^{9), 10)}$ suggest that the process could also be used in the case of larger grit size (\#120), but no clear results are included.

The EDD (Electro Discharge Dressing) process works very much like EDM does. Controlled discharges are established in a dielectric medium between a conductive electrode and the wheel (bonding material must obviously also be conductive). It was introduced by Uematsu et $a l^{12)}$, and today it has become a simple, precise and low cost trueing/dressing method ${ }^{13)}$. Quite a lot of research work has been done on the optimisation of EDD, covering aspects such as the performance of different electrode materials, dielectric fluids, discharge parameters, etc. ${ }^{13), 14), 15), 16), 17)}$.

At the sight of the advantages that can be obtained with the application of the so-called nonconventional trueing/dressing methods, new developments can be proposed. For instance, the dressing of large-grit size wheels suitable for roughing operations. As stated before, important reductions in the cutting forces could be obtained if the grit protrusion could be maximised, and this would be especially important in the case of high removal rate operations. In a possible application, electroplated large grit-size $\mathrm{cBN}$ form wheels are being used in the aeronautical industry, the wheels being discarded after the geometry is lost. Electroplated wheels are used because of their high grit protrusion. If grit protrusion of metallic wheels could be maximised and the wheels could be efficiently dressed, important cost reductions could be obtained.

However, before industrial application, the basics of the process must be fully described and understood. In this paper, the removal mechanisms of the EDD process applied to large-grit size cBN wheels are studied. The influence of the main process variables on the removal is analysed. Following the industrial trend and the ecological guidelines worldwide towards the minimization of working fluids, two alternative dielectrics have been used: water and minimal quantity of grinding emulsion. The results when using water show the feasibility of the approach, with a drastic reduction of grinding forces if compared with those recorded with a brand new wheel.

\section{FUNDAMENTALS OF THE EDD OF LARGE-GRIT SIZE WHEELS}

As said before, little work has been done previously on the EDD of large-grit size wheels. In the EDD process, the discharge is established between the conductive elements, this is, the electrode and the bonding material. The gap, of course, is occupied by the dielectric fluid, and its size has a direct influence on the conditions under which the operation is performed.

If the grits are small enough, the gap can be effectively cleaned and the process runs smoothly. However, if grit protrusion is larger than gap size, interference between wheel and electrode occurs. In this case, the wheel "grinds" the electrode. This fact does not produce short-circuit situations because the grits are not necessarily conductive, but the chips removed from the electrode get trapped inside the gap. In other words, the cleaning of the gap becomes difficult and instability may appear.

Under these conditions, three different situations have been identified:

- Optimum EDD discharges (Figure 1.a), corresponding to a stable process.

- ECDD discharges (Figure 1.b). These occur at a voltage below the open circuit voltage, and they are due to the presence of contamination (mainly chips from the "ground" electrode) in the gap. Bonding material is removed, but control of the gap is lost.

- Short-circuits (Figure 1.c).

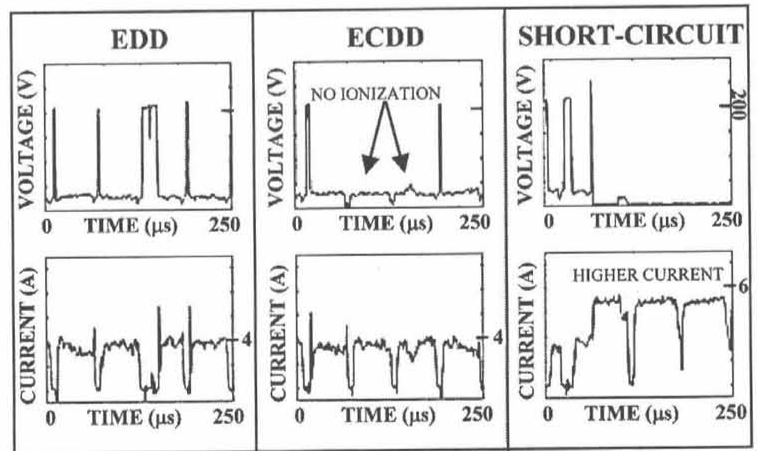

Figure 1. a) EDD discharge pattern. b) ECDD discharge pattern. c) Short-circuit discharge pattern.

The stability of the process and the bonding material removal rate are directly affected by the presence of the different types of discharges.

When dressing large-grit size wheels, the volume of bonding material to be removed is relatively large, and therefore material removal rate becomes an important consideration. However, if too much bonding material is removed, and grit protrusion is excessive, complete abrasive grits may be lost, making the dressing process inefficient. 
Therefore, it is necessary to analyse the influence of the main variables on the performance of the process, paying most of the attention at the development of the different types of discharges and at the control of bonding material removal.

\section{ANALYSIS OF THE INFLUENCE OF PROCESS VARIABLES}

\subsection{Experimental set-up}

In order to analyse the influence of the main variables on the performance of the EDD process of large-grit size $\mathrm{cBN}$ wheels, a test equipment consisting of an ONA-Datic 6D-230 SEDM machine and an electrical motor with a maximum spindle speed of $3000 \mathrm{rpm}$ was prepared. A $200 \mathrm{~mm}$ diameter cBN wheel (specification B126C75M112) was mounted on the spindle.

One of the objectives of the work was to reduce to a minimum the use of industrial oil. Literature ${ }^{13)}$ shows that attempts at dry EDD have been done, but the results have been poor in what concerns to grain exposure after dressing. However, some works have used MQL as fluid for the EDT (electro-discharge trueing) combined with ELID grinding ${ }^{18}$ with successful results but, in all the cases, the grit size of the wheels was very small. In the present paper, two ecological dielectric fluids were used: deionised water (conductivity below $2 \mu \mathrm{S}$ ) and grinding emulsion (10\% HOCUT 6000) supplied by a Minimal Quantity of Lubricant (MQL Spraymat S100) system. With this system, emulsion drops of size below $2 \mu \mathrm{m}$ are supplied into an air jet (speed $145 \mathrm{~m} / \mathrm{s}$ ) at a flow rate of $0.025 \mathrm{ml} / \mathrm{s}$.

Prior to the analysis of the most important process variables, EDM technology for bronze (wheel bonding material) using a copper electrode was developed using both dielectric fluids. Of course, the condition of erosion are not similar to those that appear during EDD, but the electrical parameters will be used later as a first approach. Moreover, it was observed that the size of the gap when using water was clearly larger than when using the MQL system. This qualitative information will be especially important when analysing the performance of the operation.

Of course, a large number of variables could have been chosen to analyse the performance of the EDD process. However, in this study the following ones have been selected, since they are directly related to the industrial application of the process and they have a straight influence on the cleaning of the working gap, and therefore, on stability and removal rate:

- Electrode size: EDD of flat wheels has been addressed. Therefore, circular electrodes covering different angles have been tested (see Figure 2).

- Wheel peripheral speed: This variable has a direct influence on the cleaning of the gap, and is specially important if in-process EDD is to be carried out.

- On-time and discharge current, which affect both the gap size and the bonding material removal rate.

Evaluation of process stability was assessed by statistical analysis of ionisation time, on-time, discharge current and classification of discharges as defined in Section 2. In order to do so, voltage and current signals were on-line recorded and analysed using a NI6115 (PCI bus) card on an industrial PC. The signal acquisition and processing utilities have been developed using Labview v6.1.

\subsection{Influence of electrode size}

Three electrode sizes were tested, covering angles of $5^{\circ}, 30^{\circ}$ and $90^{\circ}$. The results show a direct relationship between process stability and electrode size. When the $5^{\circ}$ electrode is used, the number of discharges of maximum duration (i.e., equal to ontime) is higher than when using the $90^{\circ}$ electrode. This type of discharges has been identified as ECDD type, this is, non-optimum discharges. Thus, as shown in Figure 2, in the case of the $5^{\circ}$ electrode, $12 \%$ of the discharges are non-optimum. This value decreases down to $7 \%$ for the $90^{\circ}$ electrode.

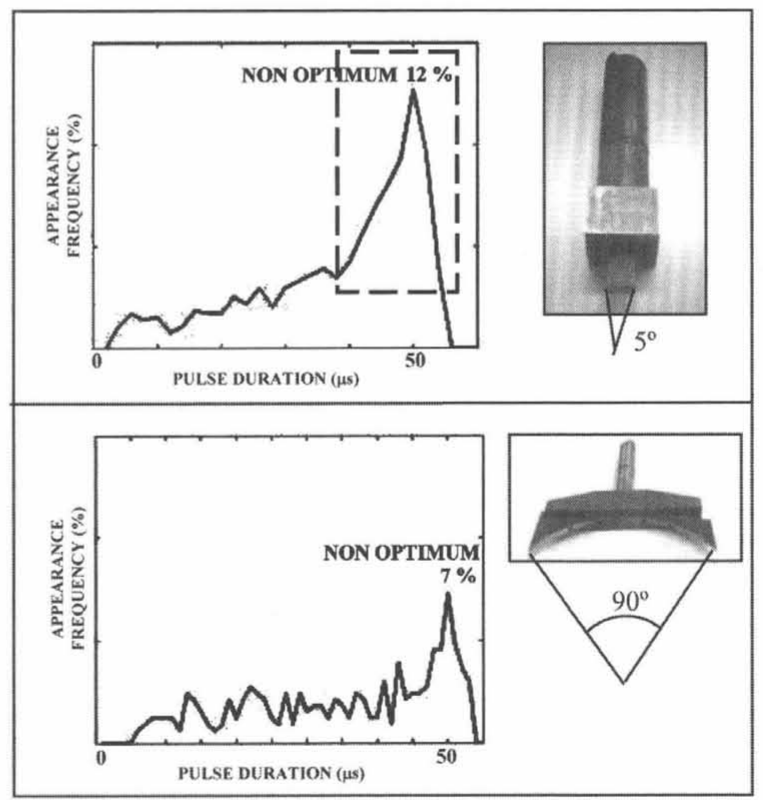

Figure 2. Appearance frequency of each pulse duration during EDD with deionised water using: a) $5^{\circ}$ electrode, b) $90^{\circ}$ electrode

This trend was even more accentuated when using the MQL system. It was not possible to stabilize the tests with the $5^{\circ}$ electrode, and although better results were obtained with larger electrodes, the stability of the process is low, the number of optimum EDD discharges being always below $70 \%$.

The above-commented effect is largely related to the radial run-out normally present in the grinding wheel, which may be as high as $20 \mu \mathrm{m}$. When using small electrodes, the readings of the servo system can not cope with the variations of the 
gap produced by the run-out, resulting in erratic movement backward-forward of the electrode. The process becomes unstable, resulting in a smaller number of discharges and in longer ionisation times (more open-circuit pulses are present). Measurements of electrode wear (which is mainly due to grinding by the wheel) confirm these results. 3.3 Influence of wheel speed

The influence of wheel peripheral speed on the process was studied, while keeping constant the rest of variables. Wheel speed values ranging from 1.4 $\mathrm{m} / \mathrm{s}$ to $33 \mathrm{~m} / \mathrm{s}$ were investigated.

Obviously, wheel speed has a major influence on the cleaning of the working gap, and therefore, on the appearance of the different types of discharges. Moreover, at high speeds the distance that the spark must "travel" is longer, which affects to the value of the discharge current. As shown in the Figure 3, a reduction of about $2 \mathrm{~A}$ is observed when moving from static erosion to $33 \mathrm{~m} / \mathrm{s}$ in both cases. Furthermore, the static erosion does not achieve a suitable cleaning in the working gap, increasing the appearance of short-circuit situations.

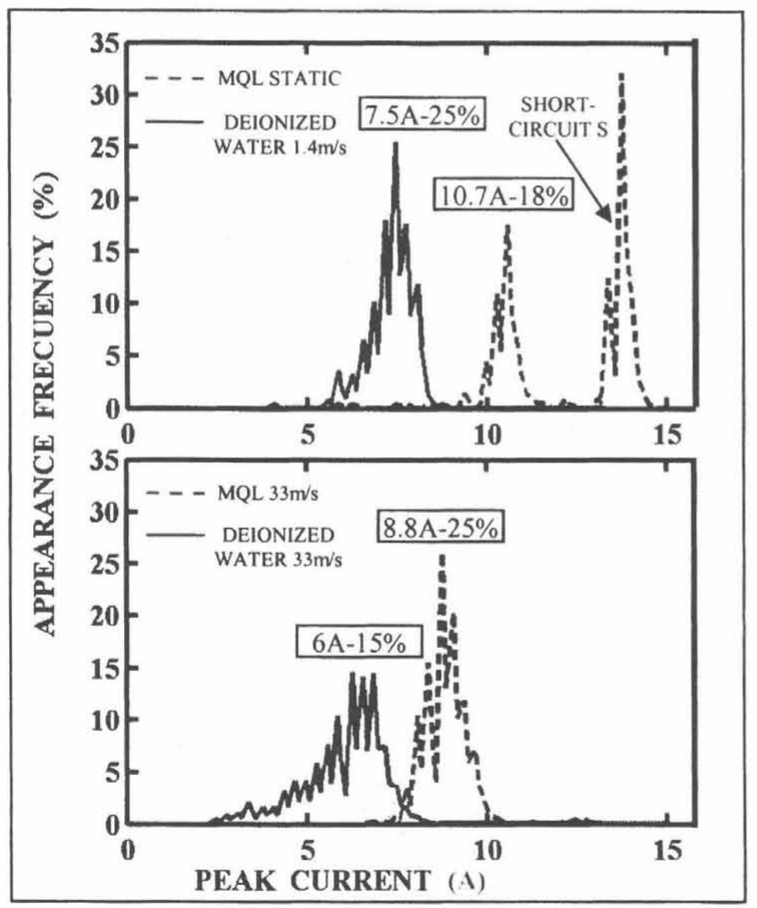

Figure 3. Influence of the wheel speed into the peak current value.

On the other side, wheel speed has a positive influence on EDD conditions. The higher the wheel speed is, the better the cleaning of the gap will be. When using deionised water as dielectric, the percentage of non-optimum ECDD discharges and short-circuits reduces from about $15.72 \%$ at $1.4 \mathrm{~m} / \mathrm{s}$ down to $5.41 \%$ at $33 \mathrm{~m} / \mathrm{s}$. Ionisation times are clearly larger at low speeds, which is also an indication of higher instability. Taking into account the reduction of current value and the increase in stability, the overall effect shows an improvement in the EDD process.

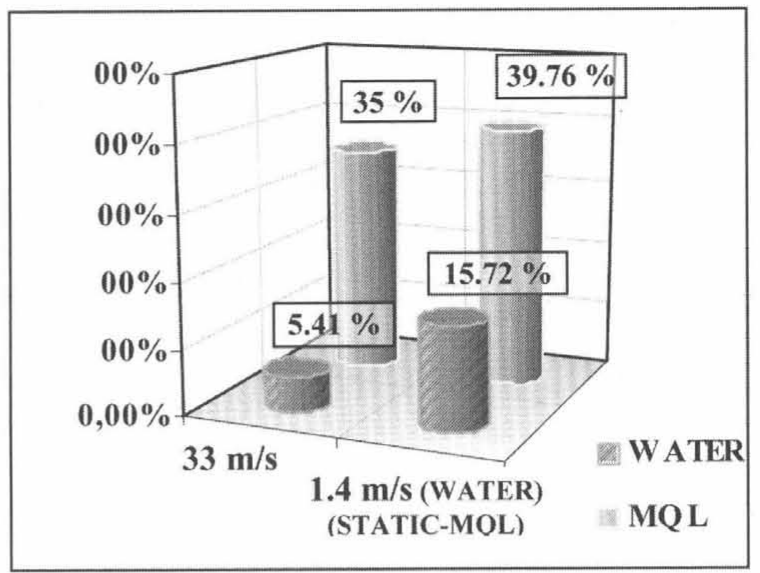

Figure 4. Influence of the wheel speed into the nonoptimum discharges.

The results also show that increasing wheel speed is not enough to improve stability when using the MQL system. The recorder number of non-optimum discharges is abnormally high, ranging from $39,76 \%$ at low rotational speed to $35 \%$ at $33 \mathrm{~m} / \mathrm{s}$ (see Figure 4). This fact is related to the small size of the working gap (which was also observed in the previous set of tests as commented on in Section 3.1) and to the poor cleaning of the gap provided by the MQL system.

3.3 Influence of on-time and discharge current

At a first glance, both on-time and discharge current should have a direct influence on the size of the gap (and therefore, on the stability of the process) and on the removal rate.

In fact, the influence on this latter is considerably more important. In order to assess that influence, a complete set of tests involving variations of discharge current (from 8 to $10 \mathrm{~A}$ ) and on-time (from 25 to $50 \mu \mathrm{s}$ ) was carried out. No significant improvements on the stability of the process in terms of percentage of optimum discharges were observed along the whole set of tests. In all the cases, carried out at the highest wheel speed $(33 \mathrm{~m} / \mathrm{s})$, stability was assured when using water, and no improvements were noticed when using the MQL system. It can be concluded that the variations tested for current and on-time are not enough to clearly increase gap size.

However, the influence of these variables on wheel bonding material removal rate can be easily noticed. Grit protrusion after EDD with both deionised water and MQL was measured using an optical profilometer for all the specimens of the above-mentioned complete set of tests. It can be concluded that bonding material removal rate increases with increases of both discharge current and on-time. As an example of the tests carried out, Figures 4 and 5 show grit protrusion after 10 minutes EDD when using deionised water and $10 / 6 \mathrm{~A}$ and $50 / 100 \mu$ s respectively. It can be noticed that as high a grit protrusion as $52 \%$ of grit size can be obtained, which means a dramatic improvement 
with respect to grit protrusion obtained by mechanical dressing.

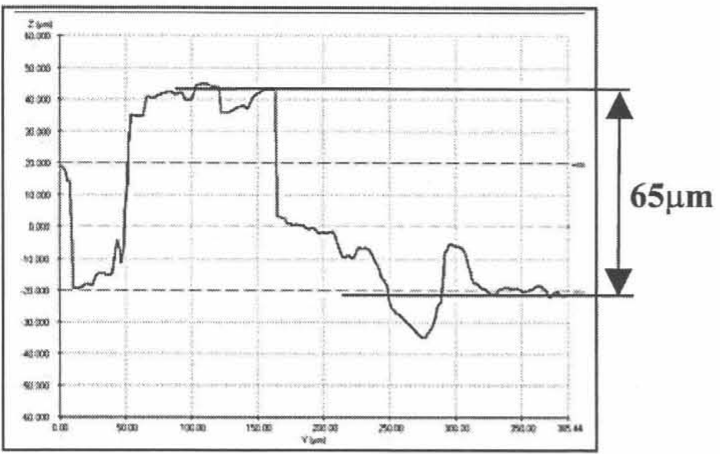

Figure 5. Profile from EDDed wheel with $I=10 \mathrm{~A}$ Ton $=50 \mu \mathrm{s}$.

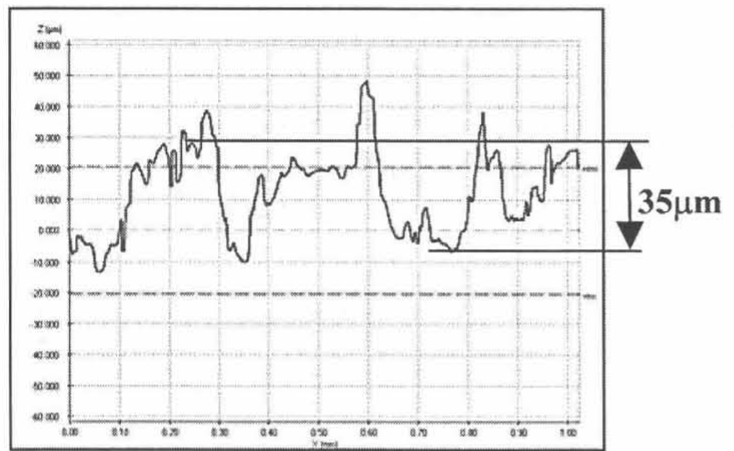

Figure 6. Profile from EDDed wheel with $\mathrm{I}=6 \mathrm{~A}$ Ton $=100 \mu \mathrm{s}$.

A negative effect was observed when using the MQL dressing system. Even though the process is very unstable, bonding material is indeed removed, but discharges tend to occur at the limits of the abrasive grits, weakening their hold by the bonding material, as shown in Figure 7. It can be stated that too much dressing around the grit is carried out, which affects negatively to future performance of the wheel during grinding. Experiments have shown that this phenomenon is difficult to be avoided, even when using low removal rate regimens.

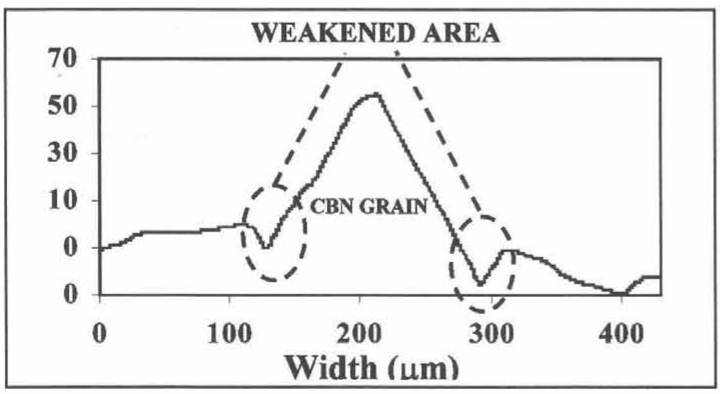

Figure 7. Example of the weakening phenomenon.

\subsection{Grinding performance of EDD'ed wheels.}

Using the information collected in the trials, it was decided to electro discharge dress B126C75M112 CBN flat wheels. Process parameters were set according to the previous EDM tests on bronze (slightly adapted to ensure process stability) using both deionised water and the MQL system. From the information gathered in the abovecommented studies, it was decided to use a $30^{\circ}$ electrode (the manufacturing costs of a $90^{\circ}$ electrode do not justify the small stability improvement), and the maximum wheel speed $(33 \mathrm{~m} / \mathrm{s})$. Discharge current was set at $10 \mathrm{~A}$ and on-time was $50 \mu \mathrm{s}$.

Grinding performance of the EDD'ed wheels was compared with that of a mechanically dressed wheel. In order to do so, grinding tests were carried out increasing the depth of cut. Workpiece material was AISI D2 tool steel. Grinding performance was evaluated by recording normal and tangential forces during the tests using a Kistler 9257B® dynamometer.

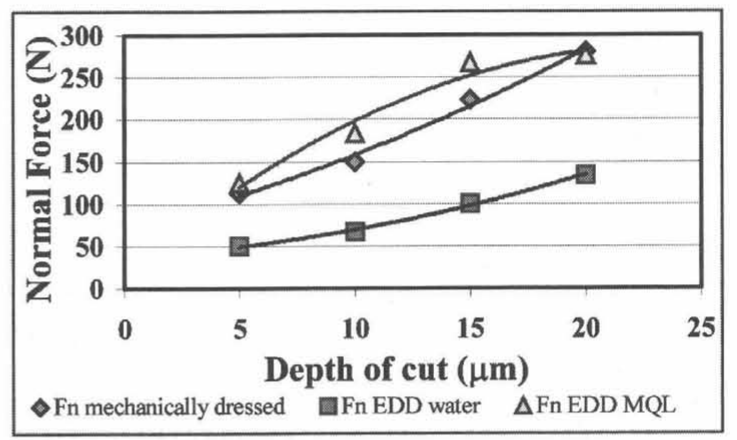

Figure 8. Comparison of the normal forces amongst different dressing methods.

Figure 8 shows the records of normal forces at different depths of cut. The results show an excellent behaviour of the water-EDD'ed wheel, with a reduction in the grinding forces as high as $42 \%$ if compared to those corresponding to the mechanically dressed wheel. This fact is related to the high grit protrusion obtained, $63 \%$ of the grit height in the case of the water-dressed wheel and $25 \%$ in the case of the mechanically dressed wheel.

The results in the case of the MQL-dressed wheel show a clear increase in the grinding forces, even if compared with the mechanically dressed wheel. This is related to the excessive grit exposure commented in Section 3.3. Complete grains are prematurely lost during grinding because too much bonding material has been eliminated from the limits of the grit (see Figure 7), weakening the wheel. The result is an increase in the grinding forces, making the operation inefficient.

\section{CONCLUSIONS}

From the work carried out, the following conclusions can be drawn:

- If grit protrusion is larger than the gap, the wheel grinds the electrode and the cleaning of the gap becomes difficult. The different types of discharges that appear under this situation have been characterized, and their relation with the stability of the process, stated. 
- Following ecological considerations, the influence of process variables on EDD performance has been studied using two ecological dielectrics: deionised water and grinding emulsion supplied by a MQL system.

- The results show that electrode size and wheel rotation speed have a direct influence on process stability. The combination of a large electrode and a high wheel peripheral speed leads to the stabilisation of water-EDD. However, when using the MQL system the stability is poor, due to the fact that the gap is too small to provide an efficient cleaning.

- As expected, bonding material removal rate can be improved by increasing electrical parameters (mainly discharge current and ontime). However, excessive grit protrusion is obtained when MQL-dressing, since material removal is concentrated in the limits of the grains. This effect weakens the wheel reducing its grinding performance.

- Grinding tests have been carried out in order to evaluate the efficiency of the EDD process. While no improvements are recorded in the case of the MQL-dressed wheels (due to the above-commented effect), large reductions (up to $42 \%$ ) in grinding forces are observed in the case of the water-dressed wheels, showing the feasibility and industrial interest of the work. This fact, is related to the high grit exposure obtained (up to $63 \%$ of grit size).

\section{ACKNOWLEDGEMENTS}

We would like to thank the Basque Government (Industry Department) and Danobat S.Coop. for their support to this work through the Research Project OD03UN49 "Analysis of the electro discharge dressing of cBN wheels".

\section{REFERENCES}

1) X. Chen; W. B. Rowem; R. Cai "Precision grinding using $\mathrm{CBN}$ wheels". International Journal of Machine Tool and Manufacture, Vol. 42, pp. 585-593, 2002.

2) R. Holz; J. Sauren "Grinding with diamond and CBN". Winter diamond tools, CBN tools, 1988.

3) R. Murata; K. Okano; C. Tsutsumi "Grinding of structural ceramics". Milton C. Shaw Grinding Symposium PED 16, pp. 261-272, 1985.

4) H. Ohmori; T. Nakagawa "Mirror surface grinding of silicon wafers with electrolytic inprocess dressing" Annals of the CIRP. Vol. 39 (1), pp.329-332, 1990.

5) H. Ohmori; T. Nakagawa "Analysis of mirror surface generation of hard and brittle materials by ELID (electrolytic in-process dressing) grinding with superfine grain metallic bond wheels", Annals of the CIRP, Vol.44, pp.287290, 1995.
6) H. Ohmori; T. Nakagawa "Utilization of nonlinear conditions in precision grinding with ELID (electrolytic in-process dressing) for fabrication of hard material components", Annals of the CIRP, Vol.46 (1), pp.261-264, 1997.

7) H. Ohmori; W. Li; A. Makinouchi; B.P. Bandyupadhyay "Efficient and precision grinding of small hard and brittle cylindrical parts by the centrerless grinding process combine with electro-discharge truing and electrolytic inprocess dressing", Journal of Materials Processing Technology, Vol.98, pp.322-327, 2000.

8) Yu. A. Pachalin "Contact erosion dressing of diamond wheels with face working surfaces". Stanki i Instruments, nº 1, pp. 20-21, 1987.

9) M. Kubota; Y. Tamura; T. Okita "Electrocontact-discharge dressing of metal bonded diamond grinding wheels using twin electrode system". ISEM IX, pp. 22-25, 1989.

10)J. Tamaki; T. Pearce "Electrocontact discharge dressing of metal-bonded diamond wheel for surface grinding". Advancement of Intelligent Production, pp. 309-314, 1994.

11)H. K. Tönshoff; T. Friemuth "In-process dressing of fine diamond wheels for tool grinding". Precision Engineering, Vol. 24, pp. 58-61, 2000.

12)K. Suzuki; T. Uematsu "On-trueing/dressing of metal bond grinding wheels by electro-discharge machining". Annals of the CIRP, Vol. 36, pp. 115-118, 1987.

13)D. Z. Chen; Y. Y. Tian "Form dressing of metalbonded diamond wheel”. ISEM IX, pp. 18-21, 1989.

14)M. Iwai; M. Ichinose; H. B. Qun; K. Takeuchi; T. Uematsu; K. Suzuki "Application of fluid-free EDM to on-machine trueing/dressing for superabrasive grinding wheels". ISEM XIII, pp. 371-380, 2001.

15)X. Wang; B. Ying; W. Liu "EDM dressing of fine grain super abrasive grinding wheel". Journal of Materials Processing Technology, Vol. 62, pp. 299-302, 1996.

16)E.-S. Lee; S.-O. Ahn "Precision surface grinding of $\mathrm{Mn}-\mathrm{Zn}$ ferrite with in-process electrodischarge dressing (IEDD)". International Journal of Machine Tools and Manufacture, Vol. 39, pp. 1655-1671, 1999.

17)P. Koshky; V. K. Jain; G. K. Lal "Mechanism of material removal rate in electrical discharge diamond grinding". International Journal of Machine Tools and Manufacture, Vol. 36, $\mathrm{n}^{\circ} 10$, pp. 1173-1185, 1996.

18)Y Pan.; T. Sasaki; N. Ito; H. Ohmori; Y. Yamagata; Y. Uehara; W. Lin, "An ELID Grinding System with a Minimum Quantity of Lubricant", Key Engineering Materials, Vol.238239, pp.23-28, 2003. 